\title{
Analysis of the Spread of Experimental Animated Short Films in the Context of New Media
}

\author{
Liang Li \\ Dalian Neusoft University of Information \\ Dalian, China
}

\begin{abstract}
Experimental animated short films, with pioneer spirit, are an important part of the cultural industry. In the past, they can be spread through traditional media. With the birth of new media, including computer media, online media, virtual reality media, and augmented reality, the spread efficiency and channels of communication have been expanded. At the same time, we should also improve the content and quality of the experimental animated short films so as to create a good effect that can be reflected in each other.
\end{abstract}

Keywords—new media; experimental animated short film; spread

\section{INTRODUCTION}

Animation is the result of the combination of art and technology. The development of animation is accompanied by the history of the development of human culture and art. From the Renaissance period, Western painting began to show the true performance of spatial light and shadow, and it became more realistic in the 19th century. However, the invention of photography technology shakes Western realism which aims at imitating the reality of natural restoration. The introduction of art from the East and Africa has also brought new interest and inspiration to painting and the attention of painting to human intuition and in-depth consciousness. Thereafter, impressionism, fauvism, cubism, expressionism, abstractionism, futurism, Dadaism, surrealism, and abstractionist school came into being successively. Although the principle of animation is different from shadow art, it uses visual effects to create visual effects. In the context of new media, with the help of modern technology, on the one hand, traditional media such as television and movies are used to spread experimental short films. It can also be spread through the Internet, mobile communications, augmented reality, virtual reality, and holographic projections.

\section{CUlTURAL COMMUNICATION OF EXPERIMENTAL}

\section{ANIMATED SHORT FILMS IN THE CONTEXT OF NEW MEDIA}

Animation is a comprehensive art of which the artistic content includes politics, literature, art, and technology. The experimental animated short film is an animated creation with pioneer spirit. It challenges the conventional production methods, successful forms of creation, themes, and narrative methods, which is the art of the creator who is dancing with shackle. American animation artist Preston Blair said in his book Cartoon Animation that "animation is both art and technology. It is a method that includes the integrated skill of cartoonists, illustrators, painters, playwrights, musicians, photographers, and film directors, etc. These comprehensive skills of artists constitute a new type of artist - animator" [1] With the continuous improvement of film technology, the appeal of experimental animation has gradually increased. The birth of new media does not have the purpose of replacing traditional media, but assists the extension and expansion of experimental animated short films in the forms and methods of communication, and better conveys the creators' thoughts and artistic ideas.

\section{THE TECHNICAL COMMUNICATION EXPERIMENTAL} ANIMATED SHORT FILM IN THE CONTEXT OF NEW MEDIA

\section{A. Discovery of Visual Staying Phenomenon (Duration of Vision)}

The phenomenon of visual persistence was first discovered by the Chinese, and a lantern adorned with a revolving circle of paper horses was the earliest use of visual staying in historical records. Then Paul Rogue, the Frenchman, invented the photo disk in 1828. It was a disk that was crossed on both sides by ropes. A bird was painted on one side of the dish and an empty cage was painted on the other side. When the disk rotates, the bird appears in the cage. This proves that when the eye sees a series of images, it keeps one image at a time [3].

\section{B. The Involvement of Film Technology}

From 1872 to 1878 , nineteenth-century British film and animation pioneer Edward Muybridge successfully shot a series of horse running photos after several experiments. This is the earliest record of continuous action. Ten years later, Thomas Edison invented the first continuous-screen recording instrument - camera in his laboratory, but this invention was not taken seriously in Edison's many inventions. In 1895, the patent right of camera was bought by the French Lumiere brothers. (Auguste Marie Louis Nicholas, 1862-1954; Louis Jean, 1864-1948), and they play the film they took, such as "The Arrival of a Train", "factory gate", etc., and thus, the first movie in the world was born in a French cafe. 


\section{The Development of Film Animation}

At the beginning of the birth of "The Humorous phases of Funny Faces" and "Fantasmagorie", the single-frame shooting method of animated paper was used. In 1915, Earl Hurd discovered that celluloid film could replace animated paper to draw characters' movements on celluloid film and the background individually on the animated paper, separating the characters from the background. In the use of camera shooting film and background animation paper overlay effect, the invention of this technology initiated the exploration of animation.

\section{The Development of Computer Technology}

In 1962, the electric calculator was invented and had its own graphics theory basis, but it was only used in the military field. In the 1960s, George Capps, a famous artist and design master established a specialized institute for the study of computer graphics art, but it was not until the birth of microcomputers in the late 1970s that computer graphics began to move from the altar to folks. Computer coloring and three-dimensional models were successively applied to microcomputers and computer graphics technology penetrates into every field: artistic pursuit, scientific and technological exploration, industrial design, graphic design, and animation production.

\section{E. The Development of Digital Animation Technology}

With the maturity of computer graphics processing technology and the popularity of personal computers, excellent graphics software has also developed rapidly. The two kinds of most famous software at present include Adobe's Photoshop in the United States, which depends on its powerful professional graphics and image editing functions. It can make art design and original animation to animation. The other is Paint of a Canada company Corel. It provides a variety of graphics algorithms virtual painting mode, such as the effect of oil painting, gouache, and crayons, etc. Through the Paint people can carry out various styles of painting on the computer.

\section{F. The Development of Two-dimensional Vector Animation Production Technology}

Flash was originally developed by Macromedia and consists of Dreamweaver, Fireworks, and Flash It is commonly known as the Three Musketeers. Initially, Flash was released only as a plug-in for webpage to play the file, but it was quickly welcomed by the creators of personal platform animation because of the advantages of high picture quality based on mathematical vector calculation algorithm, resolution ratio not being adjusted with the enlargement and reduction of the page, small file space it occupied and fast transmission speed in the network; this software was acquired by the famous Adobe company in 2006. Combining with Adobe's star product Photoshop and Illustrator, with better compatibility and conversion interface, it creates the possibility of personal platform to create vector animation. Flash uses the principle of creating key frame between two points and making tween animation through computer technology according to the principle of shooting animation frame by frame, which is very suitable for individual users to create animation. Although it is not as famous as Animo and Toons and is used by many well-known animation studios, because it has its own drawing software on the interface, and does not require a timetable, the effect of creation can be previewed in real time. Along with the update of the later multi-platform playback technology, now the files produced by Flash can be played on television and other media players directly, and therefore a large number of experimental animation short film are applied to public service, public media and other fields. With its simple and convenient features, Flash greatly reduces the production cost and time of experimental animated short films and becomes the new favorite of experimental animation. Flash competitions have also been established around the world, such as the New York Flash Video Contest, shown in "Fig. 1", by Häyhä, the winner of the competition in 2003. "I Love Death" is a nonmainstream experimental animation that is forbidden for those under 18 with the current pop word. In short four minutes, a black-and-white world, experienced a reincarnation. The lazy life is like a game, which involved violence, religion, sexuality, and life cycle.

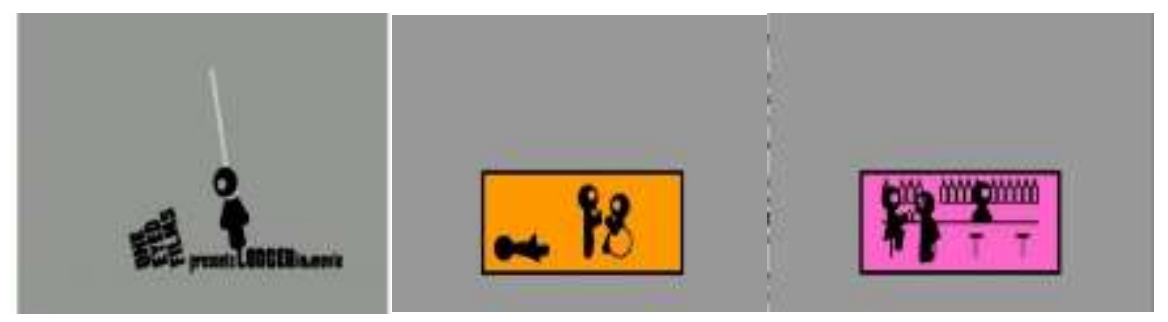

Fig. 1. Screenshot of "I LOVE Death" flash animation, 2003, 4 minutes, author Häyhä.

\section{G. The Development of 3D Animation Technology}

3D Studio Max, commonly known as 3Dmax, is 3D software developed by Autodesk based on PC (Personal Computer) platform. Previously, 3D rendering and model materials have monopolized in SGI (Silicon Graphics) graphics workstations. After the advent of Windows NT, the threshold for $3 \mathrm{D}$ production was reduced and it was widely used in the production of experimental animated short films. Maya was the top 3D animation production software of Alias. It was acquired by Autodesk on October 4, 2005 for US\$182 million. At this point, the top personal 3D software based on PC platform and Windows system went into the folk. 3Dmax and Maya continue to learn from each other's commands and operations. Its excellent 3D modeling function can realize the copy from the scene to the character. Texture material 
and lighting system combined with the excellent Vary renderer achieve real-world restoration, and its excellent SSS. Materials (simulated skin, candles and other semi-transparent effects) and physical skylight system are also a great cheer for many excellent experimental animation enthusiasts. As shown in "Fig. 2", this is the work of Chinese 3DCG artist $\mathrm{Xu}$ Fei[4]. This series "Elegant Dancing" is done by Maya software of Autodesk. In addition, the 3Dmax and Maya's respective skeletal systems can adjust the movement of the characters combining the movement rules. In addition, Maya comes with seven modules: Surface (NURBS surface module), Polygons (polygons model), Animation, Dynamics, Rendering and Dynamics, and experimental animations are based on these modules.
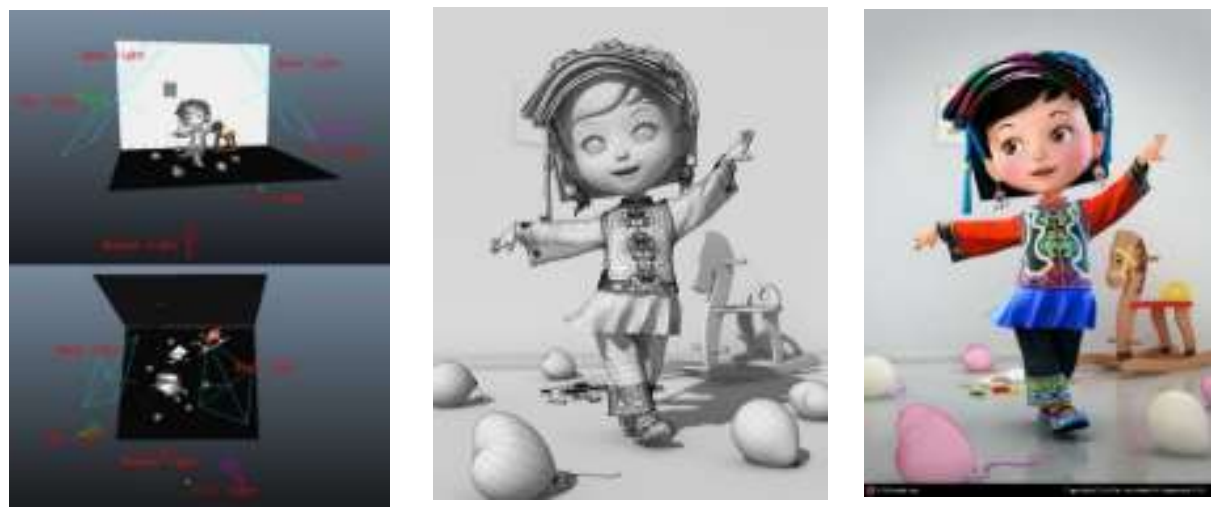

Fig. 2. Elegant Dancing, Xu Fei, 2010.

\section{H. The Development of Network Technology}

With the invention of computer technology and the rapid development of network technology, the continuous improvement of the speed of the Internet is one of the feelings of people in modern society. The rapid development of network has not only changed people's communication and chat methods, and changed the transaction method of people, but also affects people's learning methods. Previous precious animation resources and animation materials were only available to the library or spent expensive money. The development of the network favored the new generation of passion for experimental animation. The creators of the new generation can easily share the viewing experience with the people on the other side of the globe. The exchange of resources just needs a few mouse clicks; precious learning materials and master works can also be downloaded or played online; excellent individual experiment animation works can also be shared through online video display communities or platforms; experimental animation short films created by individuals or small teams can be shared with the public through the Internet.

\section{3D Stereo Film Technology}

As early as 1936, experimental animation masters made use of dual-lens cameras and polarizers to create threedimensional films. A three-dimensional movie is a movie that produces a three-dimensional effect by focusing the view difference between the left and right eyes of a person on one point. Based on the current technological developments, there are already many $3 \mathrm{D}$ movie theaters or 3D TV sets, but a large number of 3D movies are urgently needed. Therefore, these advancements in technology have led to the production of more 3D stereoscopic animated short films.

\section{J. VR Virtual Reality, AR Augmented Reality, and Holographic Projection}

Spielberg's "Ready Player One" in 2018 shows a VR virtual reality gaming experience and visual wonders. From "Avatar" 3D movie to technological progress of VR wear equipment, to the experiment animated short film with naked eye AR augmented reality produced by MagicLeap, in the basketball court, a whale jumped out of the water, with sounds and imagine coexisting, aroused the appraise of whole audience. These are the typical examples of combination of art and technology assisting the spread of experimental animated short films.

\section{CONCLUSION}

The creation of the experimental animated short film always pays more attention to content than to the form. In spite of the diverse and advancing technology, the culture, national style, experimental techniques and emotions conveyed by the experimental animation are what can impress people most and arouse resonance. Animation creates movement and animation gives life. The famous master of animation McLaren once said that "people who make animations are creating the world as the God". The essence of experimental animation is to represent images that cannot be achieved in live movies, and provide more exciting image expressions than storytelling. The truly good works cannot be copied, so only personally watching can feel the taste.

\section{REFERENCES}

[1] Jia Fou, Lu Shengzhang Introduction to Animation Beijing: Beijing Broadcasting Institute Press. 贾否, 路盛章 动画概论 北京: 北京 广播学院出版社.

[2] The importance of pre-production in the process of animation production Lv Yanmei; Zhang Fan; 《Journal of Hengshui 
University 》-2011-06-20. 前期制作在动画制作过程中的重要

性 吕艳梅; 张帆;-《衡水学院学报》-2011-06-20

[3] Http://baike.baidu.com/view/707619.htm Baidu Encyclopedia.

[4] http://forums.cgsociety.org/showthread.php?f=121\&t=919094. 